\title{
ROOT CANAL CONFIGURATION EVALUATION ON THE BASIS OF SECTIONING AND CLEARING TECHNIQUES
}

\author{
S.M Farooq ${ }^{1}$, Tahir Ali Khan ${ }^{1}$, Owais Farooq ${ }^{1}$ \\ 1. Sardar Begum Dental College
}

\begin{abstract}
Objectives:

Determination of Root canal configuration of maxillary first and second molar teeth was the aim of this study.

Study design: An in vitro experimental study.

Place and duration of the study:

Study was conducted in Gandhara University for a period of six month.

Materials and Methods:

Specimens were analyzed by sectioning and clearing techniques for evaluation of the pattern and configuration of roots. Dye penetration was the criteria which were then evaluated through microscope.

\section{Results:}

In clearing group, type-I canals are $18 \%$ more than sectioning group. While type-Il was reversely i.e. $19 \%$ more in sectioning group than clearing group.

\section{Conclusion:}

Difference in both the study groups could be mainly due to failure of dye to pass through sclerosed or minute diameter secondary canal in clearing group. This study verifies that method of research has great influence on the results.
\end{abstract}

Key words: canal configuration, maxillary molars, mesiobuccal root, clearing technique,

Correspondence:

S.M FAROOQ

CONTACT: 0333-9216562,EMAIL: awaisfaroq@yahoo.com

https://doi.org/10.37762/jgmds.1-1.72

\section{INTRODUCTION}

In sixteenth century Vesalius, Fallopus and Eustachius described the pulpal anatomy. Peter Van Foreest in 1902 was the first to speak of root canal therapy. He suggested that the tooth be trephined and pulp chamber filled with theriak ${ }^{1}$. Hollow tube theory ${ }^{2}$ compelled the research workers in the field of endodontics to design special instruments for root canal preparation, to work on root canal filling materials and to formulate appropriate sealers to hermetically seal the canals. For successful endodontic treatment skill of the Operator and knowledge about the root canal morphology are two major requirements ${ }^{3}$. Ethnic variations may also influence and were considered in studies. ${ }^{4}$ Permanent maxillary molars usually have three separate roots, two buccal and one palatal. ${ }^{5}$ 
The palatal root is the strongest and the longest. It tappers towards the apex and is smoothly rounded. Disto-buccal root is the smallest, slender and smoothly rounded. ${ }^{6}$ Mesiobuccal root is usually not as long as lingual root but is broader bucco-lingually. It has broad, flat and often fluted effect ${ }^{7}$.

Root canal anatomy may present clinicians with a complex clinical challenge that requires diagnostic approaches, access modification, and clinical skills to successfully localize, negotiate, disinfect, and seal the root canal system. Hence, this study was performed to facilitate practitioners.

There are likely to be greater variations in the canal form in mesio-buccal root of maxillary permanent molars and the mesio buccal root canal often has supplementary branches ${ }^{5}$. This study evaluated the variations of roots found in first and second molars especially in maxillary.

\section{MATERIALS AND METHODS}

In this study a total of 225 extracted human maxillary molars (first and second) were fixed in $10 \%$ formalin immediately after extraction.. The teeth were randomly divided into two groups and the root canal configuration of mesio-bucal root was examined with the help of sectioning techniques and clearing technique.

In the clearing technique (modified from Seeling ${ }^{8}$ ) 125 teeth were placed in $5 \% \mathrm{HCL}$ and the acid was changed daily until the teeth were decalcified. The decalcified teeth were washed in tap water for two hours to remove excess acid, and then the teeth and pulp tissue were made alkaline by placing them in a $10 \%$ solution of $\mathrm{NaOH}$ for 24 hours (seeling ${ }^{14}$ left the teeth in concentrated solution of $\mathrm{NaOH}$ for six hours). The teeth were washed in tap water for one hour to remove excess sodium hydroxide. Hematoxylin was injected with the help of a 27 gauge needle directly into pulp chamber through a hole in the dentin of crown and forced through the canals until the dye could be seen at the foramina. The excess dye covering the tooth was removed or decolorized by wiping the involved surface with a cloth soaked with $5 \%$ $\mathrm{HCl}$. After cleaning the surfaces, the teeth were dehydrated in ascending concentrations of $70 \%, 95 \%$ and absolute alcohol. The

teeth were then placed in xylene which made the teeth transparent after approximately two hours.

The cleared specimens were examined under a low power microscope to determine the root canal morphology of the mesio buccal root. The root canal configuration was classified into four classes as described by Weine ${ }^{9}$ due to its easy approach towards understanding and communication.

TYPE I - $\quad$ Single canal from pulp chamber to apex.

TYPE II - $\quad$ Two separate canals leaving the pulp chamber but merging short of apex.

TYPE III - Two separate canals leaving the pulp chamber and existing as separate in the root ending in separate apical - foramina.

TYPE IV - One canal leaving the pulp chamber but dividing short of the apex into two separate canals with separate apical foramina.

In the sectioning technique, one hundred extracted teeth were similarly stored in $10 \%$ formalin but decalcified in $5 \%$ solution of nitric acid. 
The nitric acid was change daily and agitated manually at different intervals. The completion of decalcification was tested by probing the crown of the tooth with the help of sharp explorer. If the decalcification was incomplete, the teeth were further subjected to the action of $5 \%$ nitric acid. After completion of the decalcification the mesio buccal roots of the teeth were sectioned off with the help of thin fissure bur. The miesio buccal root was then embedded in a block of paraffin wax and a V-shaped notch was cut into the block for orientation purposes. With the help of microtome mesio distal cross cut sections were made of $0.5 \mathrm{~mm}$ thickness. The sections numbering approximately 20 per root were arranged in sequence up on a glass slide for examination under a microscope.

\section{RESULTS}

\section{CLEARING TECHNIQUE}

Transparent maxillary molars were examined under dissection microscope for different canal configuration. The data was recorded. The summary of the data collected is in Table-1. $54.84 \%$ teeth are having only one canal in mesio-buccal root of maxillary molars and $45.17 \%$ are having two canals in different shape.

TableNo.1:

\begin{tabular}{|l|l|l|l|l|}
\hline Total & Class-I & Class-II & Class-III & Class-IV \\
\hline 124.00 & 68.00 & 32.00 & 20.00 & 4.00 \\
\hline Percent & 54.84 & 25.81 & 16.13 & 3.23 \\
\hline
\end{tabular}

SECTION TECHNIQUE

Mesio-buccal roots of 100 maxillary molars were sectioned and studied with the help of dissecting micro scope for different canal configurations (Weine's classification). The data collected can be seen in Table-2.

Table.No.2:

\begin{tabular}{|c|l|l|l|l|}
\hline Total & Class-I & Class-II & Class-III & Class-IV \\
\hline 100.00 & 37.00 & 45.00 & 16.00 & 2.00 \\
\hline Percent & 37.00 & 45.00 & 16.00 & 2.00 \\
\hline
\end{tabular}

These results are graphically depicted in figure-1 for clearing technique and figure- 2 for sectioning technique. By comparing the results of the two groups it can be seen that there is big difference in the incidence of class-I and class-II canals in the two groups, which is graphically depicted in table No.3.

\section{STATISTICAL ANALYSIS}

The Chi-square Goodness-of-Fit test was performed and the results are shown in table-3. The sectioning technique has been used as standard technique. The results obtained in the typeI and type-2 are found statistically different. 
Table No.3: Chi-Square Goodness-of-Fit Test

\begin{tabular}{|l|l|l|l|}
\hline Type (Weine) & $\begin{array}{c}\text { Observed Frequency } \\
\text { (Clearance) }\end{array}$ & $\begin{array}{c}\text { Expected Frequency } \\
\text { (Sectioning) }\end{array}$ & Chi-Square \\
\hline 1 & 55 & 37.0 & 8.660177 \\
\hline 2 & 26 & 45.00 & 8.18347 \\
\hline 3 & 16 & 16.0 & 0.00106 \\
\hline 4 & 3 & 2.0 & 075645 \\
\hline
\end{tabular}

Chi-Square $=17.5427$ with 3 d.f.

Sig. Level = 5.4645E-4

Fig.1: Clearing technique distribution

DISTRUBUTION OF DIFFERENT CLASSES CLEARING
TECHNIQUE


Fig.2: Sectioning technique distribution

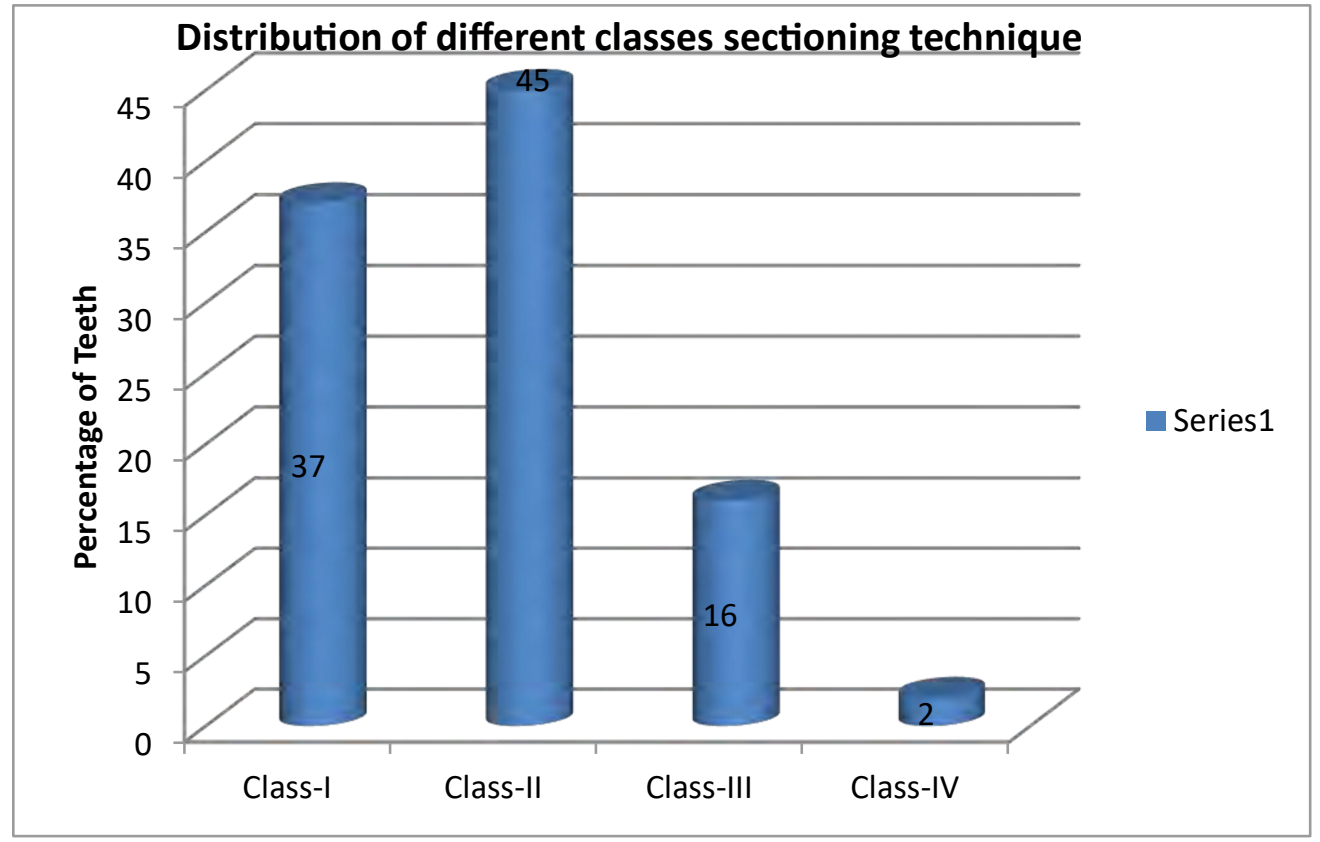

Fig.3: Comparison of clearing and sectioning techniques

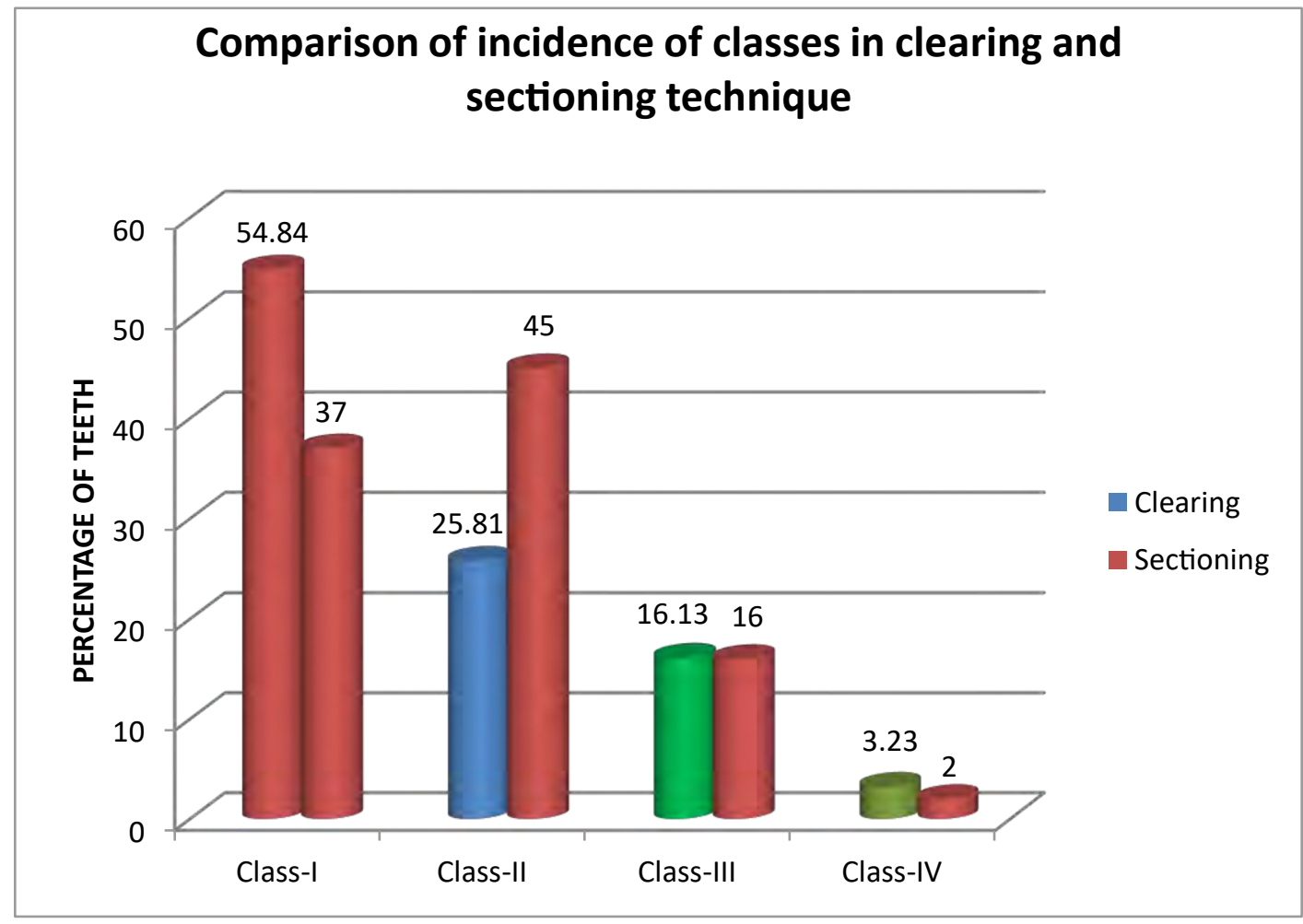




\section{DISCUSSION}

A comparison of results obtained using two different techniques clearly indicates the difference in the incidence of two canals in the mesio-buccal root of maxillary molars.

As can be seen in figure-3 the incidence of two canals was higher in the sectioning group $(63 \%)$, when compared to the clearing Group (45\%). Since the samples for both the groups were derived from the same population, the difference in the results could be attributed to techniques used. It is very much possible that the clearing techniques, whose results are the die to enter into them, are less reliable than the sectioning technique.

The sectioning technique is not dependant on the patency of the canals and the root canal could be clearly visualized. In the literature it a few authors have alluded to the effects of technique on the results obtained. Green ${ }^{10}$ had attributed high percentage of two canals in the pineda's study to the method used. According to him corridor shaped canals tend to appear as two separate canals on the radiograph. Our results obtained with the sectioning technique are one very close to obtained by seidberg et $\mathrm{al}^{11}$, Pineda ${ }^{12}$ and to some extent with Weine ${ }^{15}$ but very different from Green ${ }^{16}$

Comparing our results to Seidberg etal ${ }^{17}$ who used horizontal sectioning technique on 100 maxillary first molars. In their study percentage of teeth having single canal in the mesiobuccal roots is $38 \%$ which is almost identical to $37 \%$. Difference of results in other types of canals can mainly be attributed to the section size. In comparison to their $3 \mathrm{~mm}$ thick cross cuts we used $0.5 \mathrm{~mm}$ thin sections. In $1 / 2 \mathrm{~mm}$ sections reunion and division of the canals can be correctly judged, which usually take place in the apical third of the root.

Pineda ${ }^{18}$ who radiological studied 254 maxillary first molars, used different classification which can partially be converted to Weine's 12 classification. $40.4 \%$ of his study specimens were type-I which is quite close to the results of our sectioning technique. Again there is disagreement in other types of canals, and the different method of research can be made responsible for it.

Our results obtained with clearing method are more close to one reported by Vertucci ${ }^{13}$ who used to same clearing technique. He studied each maxillary molar individually and if we pool his results for first and second maxillary molars, (the teeth on which we did the study).

Beside the above mentioned there are other good reasons for variation in the results.

1. Age: The effect of age on root canal system has been studied by a number of investigators Hess $^{14}$, Barret ${ }^{15}$, Philippas ${ }^{16}$, Pineda and Kuttler ${ }^{17}$, Fitzwalter ${ }^{18}$, Thomas ${ }^{19}$ and is approved by most clinicians. The single dumb-bell shaped large canal of young individual change into two small rounded canals as the age advances.

2. Sex: Sexual dimorphism of teeth has been studied by Morrees ${ }^{20}, \mathrm{Gran}^{21}$ et al, Rosenweig ${ }^{22}$, Ditch ${ }^{23}$, and Rose, and recognized by many clinicians.

3. Population: difference in root canal anatomy may be due to the population from which the teeth were chosen. S.A. Manning ${ }^{24}$.

4. Reason for Extraction: Reason of extraction is another cause of variations in results. In carious teeth small canals usually become sclerosed due to deposition of secondary dentine, while in periodontally involved or in healthy teeth these canals remain open. 


\section{CONCLUSION}

Difference in both the study groups could be mainly due to failure of dye to pass through sclerosed or minute diameter secondary canal in clearing group.

So this study verifies that method of research has great influence on the results.

\section{REFERENCES}

1. Harty F.J. (1976) Introduction, History and scope, endodontics in clinical practice ed $1 \mathrm{JOHN}$ wright and sons first ed. P.1 - 5 .

2. Rickert U.G. and Dixon C.M. (1931). The controlling of root surgery in Transaction of Eight International Dental Congress Paris Section. 111 (a): 15.

3. Jaffrey D.Domark, john F Hatton, Roxanne P. Benison, Charles F. Hildebolt. An ex vivo comparison of digitalradiography and cone -beam and micro computed tomography in the detection of the number of canals in the mesiobuccal roots of maxillary molars. JOE. July 2013;39 (7):901-5.

4. Nur BG, Ok E, Altunsoy M, Aglarci OS, Colak M, Gungor E. Evaluation of the root and canal morphology of mandibular permanent molars in a south-eastern Turkish population using conebeam computed tomography. Eur J Dent 2014;8:154-9.

5. Al Shalabi RM, Omer OE, Glennon J, Jennings M, Claffey NM. Root canal anatomy of maxillary first and second permanent molars. Int Endod J 2000;33:405-14.

6. Walton R, Torabinejad M. Principles and practice of endodontics, 2nd ed. Philadelphia: W.B. Saunders Co., 1996.

7. Ash M, Nelson S. Wheeler's dental anatomy, physiology and occlusion, 8th ed. Philadelphia: Saunders, 2003.

8. Baratto-Filho F, Fariniuk LF, Ferreira EL, Pecora JD, Cruz-Filho AM, Sousa-Neto MD. Clinical and macroscopic study of maxillary molars with two palatal roots. Int Endod J. 2002;35:796 801

9. Scot J.H. and Symons, N.B.B. Introduction to Dental anatomy ed.5 Edinburgh, $E$ and S. Livingstone. 1967: 265.

10. Dorothy Permar An outline for dental anatomy pulp cavities of permanent teeth ed. 1 Lea and Fibiger.103.

11. Shroff, F.R. Basic dental anatomy and histology, London Henry Kempton 1966, P.213.

12. Sommer R.F., Ostrander F.D., and crowly M.C., Endodontics ed.2 philadelphia 1961 W.B. Saunder Company.

13. Gross L.I. endontic practice ed.9, philadelphia 1978 Lea and Febirger.

14. R. Pratima Shenoi and Hrishikesh M. Ghule. CBVT analysis of canal configuration of the mesio-buccal root of maxillary first permanent molar teeth: An in vitro study. Contemp Clin Dent. 2012 july-sep;3(3):277-281. 
15. Zeisz R.C. and Nurckolls, J. Dental anatomy, the form and function of permanent teeth and the form and function deciduous teeth. St. Louis, C.V. Mosby Co. 1949: 202.

16. Wolcott J, Ishley D, Kennedy W, Johnson S, Minnich S. Clinical investigation of second mesiobuccal canals in endodontically treated and retreated maxillary molars. $J$ Endod. 2002;28:477-79.

17. Seeling, A. And Gillis, R. Preparation of cleared specimens for pulp cavity studies J. Dent Res Sept. Oct. 1973: (52)1154.

18. Weine, F.S. Messing J.J. and stock C.J.R. colour Atlas of Endodontics Wolfe Medical publications Itd. $P$.

19. Green D, Brooklyn N.Y. Double canals in single roots oral surg. May 1973: 689-696.

20. Seidberg B.H. et al, JADA. 87;852:October 1973.

21. Pineda F. Roentographic investigation of the mesio-buccal root of maxillary first molar oral Surg. August 1973: 253-60.

22. Vertucci, F.J. Root canal anatomy of the human permanent teeth oral surg. 1984; 58:589-99.

23. Hess, $W$. The anatomy of root canals of the teeth of permanent denition ed. 1 London 1925 , Bale and Daielsson Ltd.

24. Barret, M.T. The internal anatomy of the teeth with special reference to the pulp and its branches. Dental Cosmos.1925; 67:417-26.

25. Philippas G.G. (1961). Influence of occlusawear and age on formation of dentine and size of pulpchamber J. Of Dent. Res. 40:1186-98.

26. Pineda and Kuttler (1972). Mesiodistal and buccolingnal roentogenographic investigation of 7275 root canals Oralsurg. Oral Medcine and Oral Pathology. 33:101-10.

27. Fitzwalter P.B. (1981). The root canal morphology of mandibular premolars MDSc. Thesis University of Melbourne, Australia. S.A. Manning article published in International Endodontic Journal Vol. 23 No.1 Jan. 1990:38.

28. Thomas J.S, et al Anatomy of the root apex and its histologic changes with age oral surg. Oral med. Oral Path. Feb. 1990:238.

29. Morrees C.F.A. (1975). The Alent dentition a correlative study of dental characteristics in an ESKimoid people PP. 77-101. Harvard University press, Cambridge Mass. S.A. Manning article in Inter. Endo. J. 23;1:Jan. 1990.

30. Gran S.M. et al X-linked in heritance of tooth size Journal of Dental Research. 1965.44: 43941.

31. RosenweiG K.A. (1970). Tooth form as distinguishing trait between sexes and human populations. J. Of Dent. Re. Vol. 49:1423-26.

32. Ditch, L.E. and Rose, J.C. A multivariate dental sexing technique. Journal of physical Anthropology. 1972. Vol. 37:61-64.

33. S.A. Manning Root canal anatomy of mandibular second molar part first. International Endodontic Journal. January 1990;23. No.1:38.

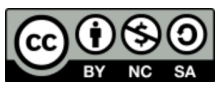

LICENSE: JGMDS publishes its articles under a Creative Commons Attribution Non-Commercial Share-Alike license (CC-BY-NC-SA 4.0). COPYRIGHTS: Authors retain the rights without any restrictions to freely download, print, share and disseminate the article for any lawful purpose. It includes scholarly networks such as Research Gate, Google Scholar, LinkedIn, Academia.edu, Twitter, and other academic or professional networking sites. 